Article

\title{
Impact of the Holistic Innovation Methodology on the Creativity Competencies of Student Mentors of the "Impulsa Peru" Recycling Program "
}

\author{
Isaac Zuñiga Aguilar 1,2,3,4,5 \\ 1 Ph.D. Fellow of University of Lleida \\ 2 Post grade Professor of Agrobusiness Master, ESAN University, Surco, Lima 15023, Peru, \\ izuniga@esan.edu.pe, izunigaa@adexperu.edu.pe, izuniga@eip.edu.pe, Tel.: +51-1980-126-810 \\ 3 Post grade Professor of ADEX, San Borja, Lima 15021, Perú \\ 4 Professor of Professional School of Business Administration, Economics Sciences Faculty of the UPAO \\ University, Trujillo 13008, Peru \\ 5 Founder Professor of Escuela de Innovadores del Perú, Lima 15076, Peru
}

\begin{abstract}
This article shows the alternative learning methodology to stimulate the holistic side of students' minds to achieve the increment of the innovation skill, managing the creative competencies and level of stress. The present research study is pre-experimental research designed with prior and posterior measurement, longitudinal, explanatory, and co-relational, with the main objective to demonstrate the effect of the holistic innovation coefficient of the beneficiaries of the program "Impulsa Peru". Program Results: It has been concluded that the experimental group is significant over the control group. Therefore, the holistic innovation methodology had an impact on the experimental group. Conclusions: Hypothesis 1 is fulfilled in which it is affirmed that the holistic innovation methodology has a positive impact on the level of coefficient of holistic innovation of the student mentors of the women recyclers of the program Impulsa Peru with a significance level of $0.05 \%$.
\end{abstract}

Keywords: innovation; holism; stress

\section{Introduction}

The phenomenon of internet-driven globalization is an irreversible process that has allowed the spread of macro trends and their influence on the dizzying behavior change of the human being in its multiple client facets such as connectivity, the Internet of the things, artificial intelligence, mass personalization, the preponderance of the design overproduction. [1] According to Xavier Ferrás, "Paradoxically, at the very moment when we realize, more strongly than ever before, that the forces of technological change and the globalization of markets convulse the world and create new economic and competitive paradigms, at the very moment when capitalism as a form of economic and social organization spreads inexorably across the globe." And after this statement we could cite [2] China as a different economic order but with similar experiences in technological changes that it has been experiencing at the level of innovation, placing it for the first time in the [3] world innovation ranking. Innovation has been the strategy used by many countries to raise productivity rates, and this effect has affected poverty reduction according to the World Bank, reducing poverty from $(42.2 \%)$ in 1981 to $(10.7 \%)$ in 2013. However, a large part of the population still lives without access to education due to a lack of resources. So, with the percentage of poor populations having no access to formal education, would they be excluded from innovating? and the possibility of escaping poverty could, therefore, be closed. To answer this question, we should explore the two areas of the brain according to Alejandro Schnarch [4] The rational hemisphere (left) and the holistic hemisphere where emotions and senses (right) are located according to Peter Senge [5]. This is why if we analyze human 
behavior taking into account Robbins' approach [6] we can identify the search for intrinsic rewards in three aspects such as cognitive aspect: Belief in being creative, self-knowledge, introspection, logical thinking-lateral, intuition-reason; the affective aspect (high self-motivation) and the behavioral aspect related to Ease to formulate problems and concretize creative pockets, Constant search for ideas, Transgressive attitude, Adventurous attitude, Creative Leadership, Know to think naively. On the other hand, if we were to complement each other to have a holistic view of the quest for extrinsic rewards, we could identify: Search for Recognition, Search for Improvement of Life. All of these variables will impact the holistic hemisphere of the brain and predispose the ability of humans to innovate, taking into account the level of stress, which can impact positively and/or negatively, according to Hunter and Thatcher [7] regarding each person's creative abilities. That is why human beings are a being with diverse intellectuals that responds to the context in which they develop and that results from interaction with this environment to develop multiple intelligences as mentioned by Howard [8].

This research study proposes a methodology whereby the sixteen competencies of the holistic coefficient of creativity are stimulated in three phases. The initial phase called "Inspiration phase" (Figure1), promotes space relations, artistic expression, creativity and emotions within the participant, without affecting the level of stress, it increases the level of inspiration, imagination and through which the point of dominance can be reached.

In the "Mastery phase" (Figure1), the participant is stimulated through the stress of the competition between teams, however, it does not stop connecting with the inspiration through the music workshop that aims to stimulate singing, music, creativity, and emotions. According to Levitin [9], "Music combines the temporal dimension of film and dance with the special dimension of painting and sculpture, replacing the three-dimensional space of visual arts with a space of heights (or frequencies).

"The auditory cortex has developed frequency maps that work analogously to spatial maps of the visual cortex". Even if at this stage the stress level is used as a stimulator, its effect could be channeled positively. According to Levitin [9] During World War II, many prisoners of German concentration camps wrote poetry, composed music, and painted, according to Victor Frankl, such activities gave meaning to the miserable existence of those dead in life. Frank and other authors have pointed out that this explosion of creativity in exceptional circumstances is usually not the result of a conscious decision to improve life or our vision of things through art. On the contrary, it presents itself almost as a biological necessity, as essential as eating and sleeping. Many artists, when abstracted in their work, forget about both. That is why one way to expose what process of creation the creative process has had is to graphically express the new concepts and this happens in the "Conceptual design phase" (Figure1). This process is based on the fact human beings have different skills to communicate such as kinesthetic abilities, hearing skills, and visual abilities according to Richard Bandler and John Grinder [10].

This research study has considered analyzing the effect of the holistic innovation methodology on the holistic innovation coefficient in a group of 8 students of the administration program of the Antenor Orrego Private University of Trujillo, Peru who would participate as mentors of 25 women that are involved in recycling within the Impulsa Peru program of the Ministry of Labor and Employment Promotion of the Peruvian State, taking into account that a profile of students of an age of 20 years, single, without and/or with work, with an average of low to medium grade 13 and who has voluntarily decided to apply to participate as mentors of 25 women from vulnerable sectors involved in recycling in the Trujillo area. 
Research Question:

Will the Holistic Innovation Methodology impact the holistic innovation coefficient on student mentors in the Impulsa Peru recycling program?

- H1: The Holistic Innovation Methodology does impact the holistic innovation coefficient of the student mentors in the Impulsa Peru recycling program.

- H0: The Holistic Innovation Methodology does not impact the holistic innovation coefficient of student mentors in the Impulsa Peru recycling program.

\section{Materials and Methods}

This research study is pre-experimental research with prior- and posterior- measurement, longitudinal, explanatory, and correlation. The main objective of this research is to demonstrate the effect of holistic innovation methodology on the holistic innovation coefficient of the Impulsa Perú program beneficiaries.

A. Population: Comprised of 120 students from the Administration program of the Antenor Orrego Private University of Peru, considered to be "mentors of Impulsa Peru" and 25 recycler women from the province of Trujillo. Source: (Ministry of Labor and Employment Promotion and database of students selected as mentors).

B. Sample size: To calculate the sample size, the formula for media comparison was used, using data from a pilot study:

\begin{tabular}{ll}
\hline Alpha (Maximum Type I error) & $\alpha=\mathbf{0 . 1} \%$ \\
\hline $1-\alpha / 2=$ Two-tailed Trust Level & $1-\alpha / 2=1.000$ \\
\hline$Z 1-\alpha / 2=$ Patterned value & $\mathrm{Z} 1-\alpha / 2=3.291$ \\
\hline Beta (Maximum Type II error) & $\beta=0.200$ \\
\hline $1-\beta=$ Statistical Power & $1-\beta=0.800$ \\
\hline$Z 1-\beta=$ Patterned value & $\mathrm{Z} 1-\beta=0.842$ \\
\hline Group Variance 1 & $\mathrm{s} 12=64.00$ \\
\hline Group Variance 2 & $\mathrm{s} 22=64.30$ \\
\hline Proposed Difference & $\mathrm{x} 1-\mathrm{x} 2=17.60$ \\
\hline Calculated size for each group & $\mathrm{n}=7.07$ \\
\hline Minimum size for each group & $\mathrm{n}=8$ \\
\hline
\end{tabular}

The minimum sample size found was 8 subjects in the experimental group who were trained by the holistic innovation methodology and 8 subjects per control group who were not trained by the holistic innovation methodology.

\section{Results}

\subsection{Experimental Group Results}

- In the experimental group, the impact of the 16 variables identified in the (y) holistic innovation coefficient of the students of the Antenor Orrego Private University increased from an average correlation level of 0.56 in the pretest to an average correlation level of 0.66 in the post-test, that is, a correlation average difference of 0.10 .

- In the experimental group, the average holistic innovation coefficient level of the post-test $(\mathrm{y} 1=$ $271)$ is greater than the pre-test $(\mathrm{y} 2=259)$ with a mean difference of 9.5 .

- In the control group, the impact of the 16 variables identified in the (y) holistic innovation coefficient of the students of the Antenor Orrego Private University increased from an average correlation level of 0.60 in the pretest to an average correlation level of 0.65 in the post-test, that is, a correlation average difference of 0.05 .

- In the control group, the average holistic innovation coefficient level of the post-test $(x 1=239)$ is greater than the pre-test $(x 2=238)$ with a mean difference of -2.13 . 
- $\quad$ The difference in the holistic innovation coefficient (y2 - y1) in the experimental group is 7 greater than the difference in the holistic innovation coefficient $(x 2-x 1)$ which is -5 .

\subsection{Figures, Tables, and Schemes}

Inspiration phase: In this phase (Figure 1) the participant initiates the learning process intuitively, connecting his inner self with his dreams, taking into account his experience as the open bases to new knowledge. Previously, it is very important to prepare the participating subject, mapping and identifying the existing blockages within its inner self that could hinder the creative process, for this purpose, it is very important to manage empathy and confidence-building by the inspiring Leader. The critical factor to be taken into account at this stage is that the experience of the participating subject could skew the way the participant subject looks and analyzes reality by the participating subject and unlock its creative process. To this end, it is essential to develop exercises that promote spatial relations by measuring the participant's skills concerning indicators such as image perception, image orientation perception, image accessibility, image perfection, connection awareness, communication flows, dependency level, creation of abstract body figures, generating various representations, imagination, creation of body figures with meaning, expression of the feeling connecting the student with purpose.

Mastery point phase: In this phase (Figure 1), the knowledge transfer by the Inspiring Leader is gradually initiated, seeking to enable the subject involved to interpret the analysis of macro-trends and problems in their environment that are the key input to initiating the disruptive process generated by the intersection of the most combinations in the "innovation tree". The student in this phase must articulate the reality for identifying the problems and then be able to interpret the association with the macro-trends to generate an appropriate disruptive process using techniques such as the per-function ratio, to promote the interpretative capacity of the student a music workshop is held to measure their performance against rhythmic identification, melodic identification, musical audition of instrumental fragments, qualifying a live audition.

Conceptual design phase: In this phase (Figure 1), the facilitator challenges the participating subject by relating it to the expected results such as qualifications, indicators, etc., and manages to convince him emotionally to manage the application of knowledge through the development of application prototypes to understand in real context the claims of knowledge. The critical factor in this phase is the management of emotion as a catalyst in the application of knowledge through indicators.

Conceptual validation: In this phase, the facilitator challenges the participant by promoting the internal competition of the teams to be able to express the most ideas through graphics, images, etc. At the end of the workshop, the key participants are recognized.

Market validation: In this phase, the facilitator asks each team to relate what changes each innovative proposal would generate in their environment, improving the quality of life.

Prototype development: In this phase, the facilitator asks each team to classify the best innovative proposals depending on the level of impact they have on improving the quality of life. He also requests for the development of a representative physical example to the idea of innovation.

In this phase, the facilitator proposes certain guidelines by which we can communicate ideas through graphical representations through a painting workshop that measures the ability to represent the student through: image perception, image orientation perception, image accessibility, image perception, generating various representations, imagination, abstract figure creation, image creation, color appreciation. 


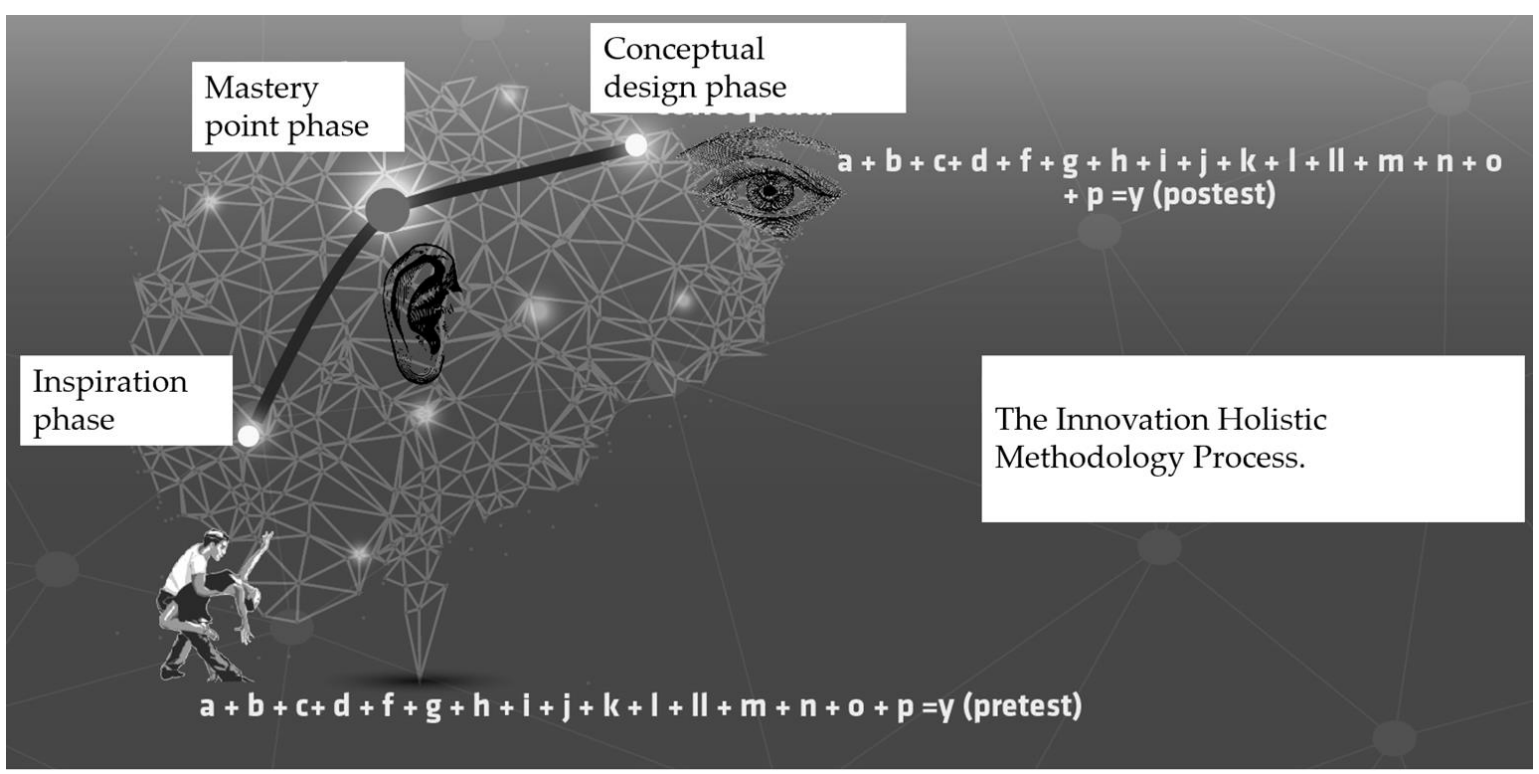

Figure 1. The Innovation Holistic Methodology Process.

Table 1. Results.

\begin{tabular}{clccccccc}
\hline \multirow{2}{*}{ Group } & $\begin{array}{c}\text { Correlation } \\
\text { variable }\end{array}$ & Median & Media & DE & Minimum & Maximum & $\boldsymbol{P}$ \\
\hline \multirow{2}{*}{$\begin{array}{c}\text { Experimental } \\
(\mathrm{n}=8)\end{array}$} & Pre-test & 0.56 & 270.00 & 264.88 & 26.05 & 219.00 & 298.00 \\
& Post-test & 0.66 & 284.00 & 274.38 & 27.62 & 224.00 & 302.00 \\
& Difference & 0.10 & 7.00 & 9.50 & 7.15 & 2.00 & 22.00 & $0.0454^{*}$ \\
\multirow{2}{*}{ Control $(\mathrm{n}=8)$} & Pre-test & 0.60 & 246.50 & 244.63 & 27.44 & 209.00 & 287.00 & \\
& Post-test & 0.65 & 246.00 & 242.50 & 24.10 & 210.00 & 278.00 \\
& Difference & 0.05 & -5.00 & -2.13 & 8.51 & -13.00 & 8.00 \\
\hline
\end{tabular}

* Test U-Mann Whitney between experimental and control group; DE, standard deviation.

\subsection{Formatting of Mathematical Components}

This is an example of an equation:

$$
\mathrm{a}+\mathrm{b}+\mathrm{c}+\mathrm{d}+\mathrm{f}+\mathrm{g}+\mathrm{h}+\mathrm{i}+\mathrm{j}+\mathrm{k}+\mathrm{l}+\mathrm{ll}+\mathrm{m}+\mathrm{n}+\mathrm{o}+\mathrm{p}=\mathrm{y}
$$

the text following an equation need not be a new paragraph. Please punctuate equations as regular text.

\section{Discussion}

To analyze the results of this research, we could take into account the limitations of inferring with a sample of eight research subjects in both the experimental group and the control group. It is important to note that in the process of research, the subjects of the research were half women and half men, with an average not outstanding and no family burden having decided voluntarily and selflessly to participate in the mentoring project with 25 female recyclers. The emotional component of the research subject with the recycling project has been fundamental to being considered in the research sample. That is why attendance has been taken into account for 100 percent of the research subjects in the experimental workshops to show the criteria of emotional connection. On the other hand, the formula for comparing averages was used to calculate sample size, using data from a pilot study with 5 research subjects, taking into account that the impact of holistic innovation methodology might be more evident in small groups.

The research process consisted of a pre-test, which assesses the situational state of the impact of the sixteen variables on the holistic innovation coefficient before any stimulus, using a questionnaire called the "Holistic Innovation Coefficient Questionnaire". Subsequently, three workshops are held such as theater, music, and painting combined proportionally with courses in systemic thinking, 
marketing for innovation, and finance to implement innovative ideas in the three phases of the methodology: inspiration phase, mastery phase, and design phase. Art is used as a powerful tool to encourage self-awareness and creative ability at the participant by stimulating the holistic appearance of the brain and impact on the sixteen variables, within which the level of stress at the inspiration phase has no participation stands out, and instead, exercises were promoted that accentuate the level of inspiration, imagination and through which the mastery point can be reached, in which the level of stress unleashes as a catalyst when combined with the music that according to Levitin "combines the temporal dimension of film and dance with the special dimension of painting and sculpture, replacing the three-dimensional space of visual arts with a space of heights". Finally, the design workshop stimulates the connection between the conceptual aspect and the visual capabilities to capture the innovative idea. Subsequently, a post-test will be applied to assess the level of impact of the sixteen variables with which a level of scoring of the coefficient is identified.

This research study shows that by stimulating the holistic side of the brain, you can achieve a higher level of holistic innovation coefficient by pre-disposing the participant to a greater creative capacity by managing the emotional aspect that impacts the sixteen variables identified in the stresshighlighting study as a factor that is recommended to remain (null) by preventing the participant from reaching a level of inspiration that enables it to achieve the highest level of creativity at the mastery point where stress could help to stimulate the creative aspect by generating a sense of pleasure in the participant.

In the pre-test, the experimental group had an average correlation coefficient of 0.56 lower than the average correlation coefficient level of the control group that resulted in 0.60 . This means that the level of holistic innovation coefficient had slightly more advantage than the sixteen competencies that were measured in the participants who were in the control group concerning the participants of the experimental group. However, in the post-test the experimental group the average correlation coefficient was 0.66 higher than the average correlation coefficient level of the control group that resulted in 0.65 . This means that the post-test has recorded that in the experimental group there has been a greater increase in the level of correlation of the sixteen variables even though in the pre-test its level of correlation was lower in the experimental group than in the control group.

The result of the application of the Holistic Innovation Methodology concludes a statistically significant impact $(\mathrm{p}<0.05)$ in the experimental group showing a greater difference in the scores after the application of the test, with average scores of $9.50(\mathrm{SD}=7.15)$ and $-2.13(\mathrm{SD}=8.51)$ respectively (Table 1).

\section{Conclusions}

It is concluded that hypothesis 1 is fulfilled.

The Holistic Innovation Methodology generated a significant impact of $0.05 \%$ on the holistic innovation coefficient in mentoring students in the Impulsa Peru recycling program. 


\section{References}

1. Ponti Franc y Ferrás, Xavier. Pasión por Innovar; Norma: Barcelona, Spain, 2008; p. 290.

2. World Bank Data. Available online: https://data.worldbank.org/ (accessed on 1 September 2017).

3. Global innovation index 2018 Energizing the world with innovation: https://www.wipo.int/publications/es/details.jsp?id=4330, , Organización Mundial de la Propiedad Intelectual (OMPI): New York, NY, USA, 2018.

4. Schnarch, A. Desarrollo de Nuevos Productos y Empresas; McGraw-Hill Interamericana: Barcelona, Spain, 2009; p. 409.

5. Senge, P.M. La Quinta Disciplina; Ediciones Granica: Ciudad de México, Mexico, 1998; p. 490.

6. Robbins. Síndrome de Burn Out: Estrés Fuera de Control. 2004. Available online: https://books.google.com.pe/books?id=OWBokj2RqBYC\&pg=PA583\&lpg=PA583\&dq=sindrome+de+burn out+robbins\&source=bl\&ots=YKaccfn61c\&sig=ACfU3U1hayXecEGmtK3sCDPF1dsJkrSJ8w\&hl=es419\&sa=X\&ved=2ahUKEwigmYibzNHmAhVWK7kGHdnFBbI4ChDoATAHegQIBxAB\# $\mathrm{v}=$ onepage\&q=si ndrome\%20de\%20burnout\%20robbins\&f=false (accessed on 1 September 2017).

7. Hunter, L.W.; Thatcher, S.M.B. Feeling the Heat: Effects of Stress, Commitment, and Job Experience on Job Performance. Acad. Manag. J. 2007, 50, 953-968.

8. Gardner, H. La Inteligencia Reformulada: Las Inteligencias Multiples En El Si Glo XXI; Paidos Iberica: Barcelona, Spain, 2001; p. 270.

9. Levitin, D.J. El Cerebro Musical: Seis Canciones Que Explican La Evolución Humana; RBA Libros: Barcelona, Spain, 2014; p. 362.

10. Bandler, R.; Grinder, J. Neuro Programming Linguistic. 1970. Available online: http://infed.org/mobi/neuro-linguistic-programming-learning-and-education-an-introduction/ (accessed on 1 September 2017). 